\title{
A COMPARATIVE STUDY OF MAGNETIC RESONANCE CHOLANGIOPANCREATOGRAPHY AND ENDOSCOPIC RETROGRADE CHOLANGIOPANCREATOGRAPHY
}

\author{
Flora Juanita Edwin'1, Arun Chelladurai ${ }^{2}$ \\ ${ }^{1}$ Associate Professor, Department of Radiodiagnosis, Government Thoothukudi Medical College. \\ ${ }^{2}$ Associate Professor, Department of Radiodiagnosis, Government Thoothukudi Medical College.
}

ABSTRACT

\section{BACKGROUND}

Magnetic Resonance Cholangiopancreatography (MRCP) is a non-invasive technique for direct visualization of biliary tree and pancreatic duct. It provides images similar to those obtained with invasive cholangiography (ERCP and PTC). Aim of the study is to compare Magnetic Resonance Cholangiopancreatography (MRCP) and Endoscopic Retrograde Cholangiopancreatography (ERCP) in the evaluation of biliary obstruction.

\section{MATERIALS AND METHODS}

The study is a prospective study of 27 cases in the age group of 22 to 65 years who were having a history of obstructive jaundice. The patients underwent MRCP and the results were compared with ERCP.

\section{RESULTS}

Of the 27 cases, MRCP picked up calculus in 12 cases. ERCP also noted calculus in 12 cases. A small CBD calculus was missed in both MRCP and ERCP. GB calculus in one case was masked in the MRCP images by the bright signal from bile in GB. But the conventional SE images and source images of MRCP were reviewed in that case and GB calculus was diagnosed in that case based on source images. Stricture was correctly noticed in 8 of the patients in MRCP as well as ERCP. Malignant tumour was diagnosed by MRCP in 6 cases, which was also noted correctly by ERCP.

\section{CONCLUSION}

The study concluded that MRCP is a superior imaging modality when compared with ERCP, mainly because it is non-invasive and can give a detailed map of biliary tree allowing visualisation of ducts proximal as well as distal to the level of obstruction. MRCP can also show the extent of lesion more accurately than ERCP.

\section{KEYWORDS}

Magnetic Resonance Cholangiopancreatography, Endoscopic Retrograde Cholangiopancreatography, Percutaneous Transhepatic Cholangiography, Biliary Diseases.

HOW TO CITE THIS ARTICLE: Edwin FJ, Chelladurai A. A comparative study of magnetic resonance cholangiopancreatography and endoscopic retrograde cholangiopancreatography. J. Evolution Med. Dent. Sci. 2016;5(89):6602-6605, D0I: $10.14260 /$ jemds/2016/1493

\section{BACKGROUND}

Magnetic Resonance Cholangiopancreatography (MRCP) is a non-invasive technique for direct visualisation of biliary tree and pancreatic duct.1,2 It provides images similar to those obtained with invasive cholangiography (ERCP and PTC).

In the evaluation of biliary tree and pancreatic duct, sonography has limitations as the bowel gas and obesity can limit the image resolution. CT scan also has limitations because cholesterol stones may be missed as their attenuation resembles fluid. Biliary strictures are also not visualised directly on CT. ERCP and PTC are invasive imaging modalities. ${ }^{3,4}$

\section{Financial or Other, Competing Interest: None.}

Submission 19-08-2016, Peer Review 12-09-2016

Acceptance 19-09-2016, Published 05-11-2016.

Corresponding Author:

Dr. Flora Juanita Edwin,

Associate Professor,

Department of Radiodiagnosis,

Govt. Thoothukudi Medical College Hospital,

Thoothukudi-628001

Tamilnadu.

E-mail: eflorajuanita@yahoo.in

DOI: $10.14260 /$ jemds/2016/1493
MRCP since its introduction by Wallner et al in 1991 has experienced remarkable growth in the diagnosis of biliary diseases. It has now assumed the position of modality of choice in the evaluation of biliary tree and pancreatic duct.5,6,7,8,9

\section{AIM OF THE STUDY}

Aim of the study is to compare Magnetic Resonance Cholangiopancreatography (MRCP) and Endoscopic Retrograde Cholangiopancreatography (ERCP) in the evaluation of biliary obstruction. Reference standards for comparison were surgery or biopsy taken laparoscopically.

\section{MATERIALS AND METHODS}

The study is a prospective study done in Government Thoothukudi Medical College from February 2016 to July 2016. Patients in the age group of 22 to 65 years who were having a history of obstructive jaundice were included in the study; 27 patients with obstructive jaundice underwent MRCP using 1.5 Tesla GE MRI Scanner; 17 were males and 10 were females. The results were compared with ERCP.

\section{FUNDAMENTAL CONCEPT OF MRCP}

Bile and pancreatic duct fluid are static and have long T2 times. Therefore, high resolution, heavily T2 weighted images display these structures as areas of high signal intensity 
against solid parenchymal organs and flowing blood with a shorter T2 or rapid dephasing. Three dimensional reconstruction algorithms can then be applied to produce image of the entire biliary tree or pancreatic duct.
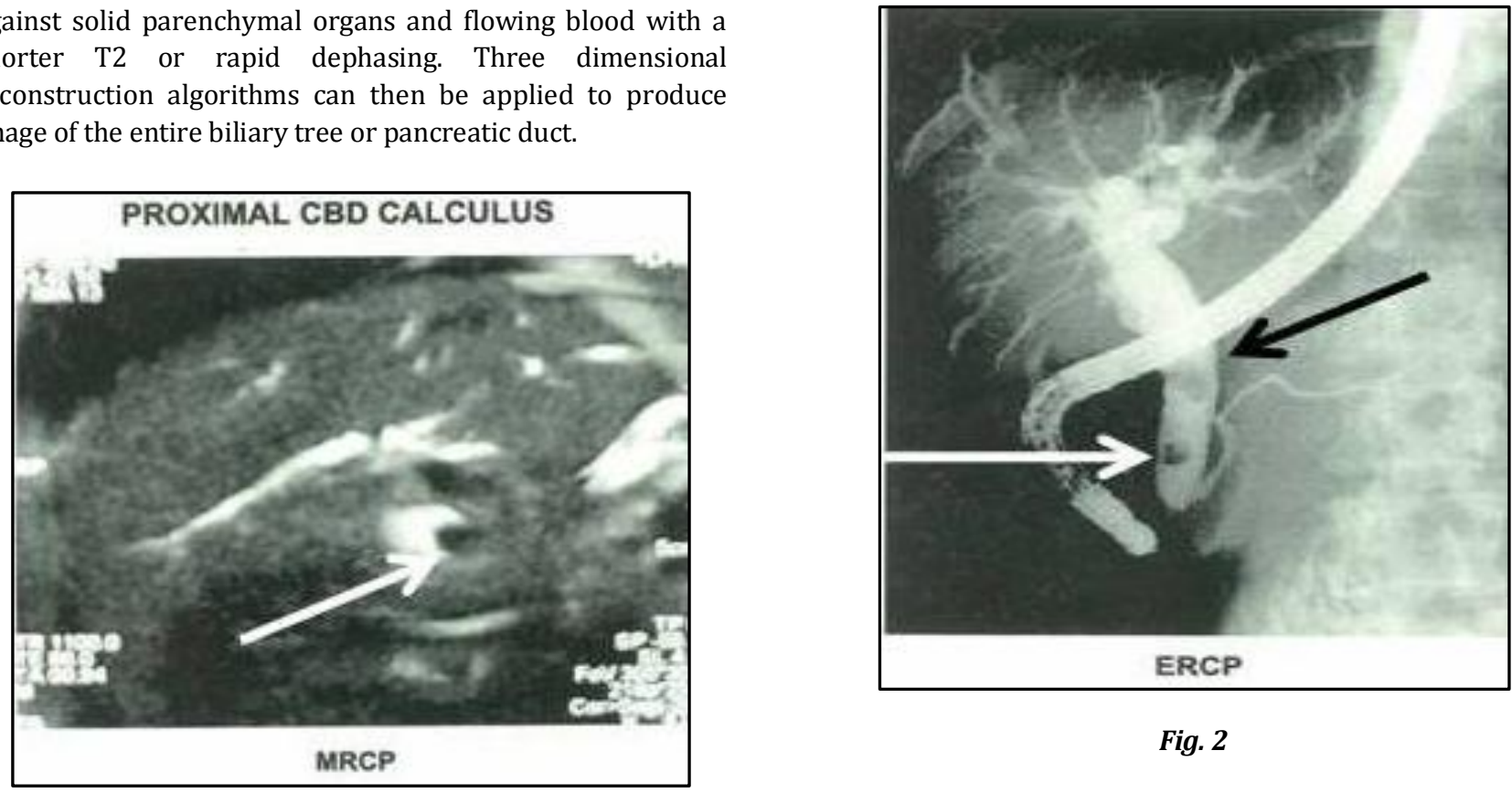

Fig. 2
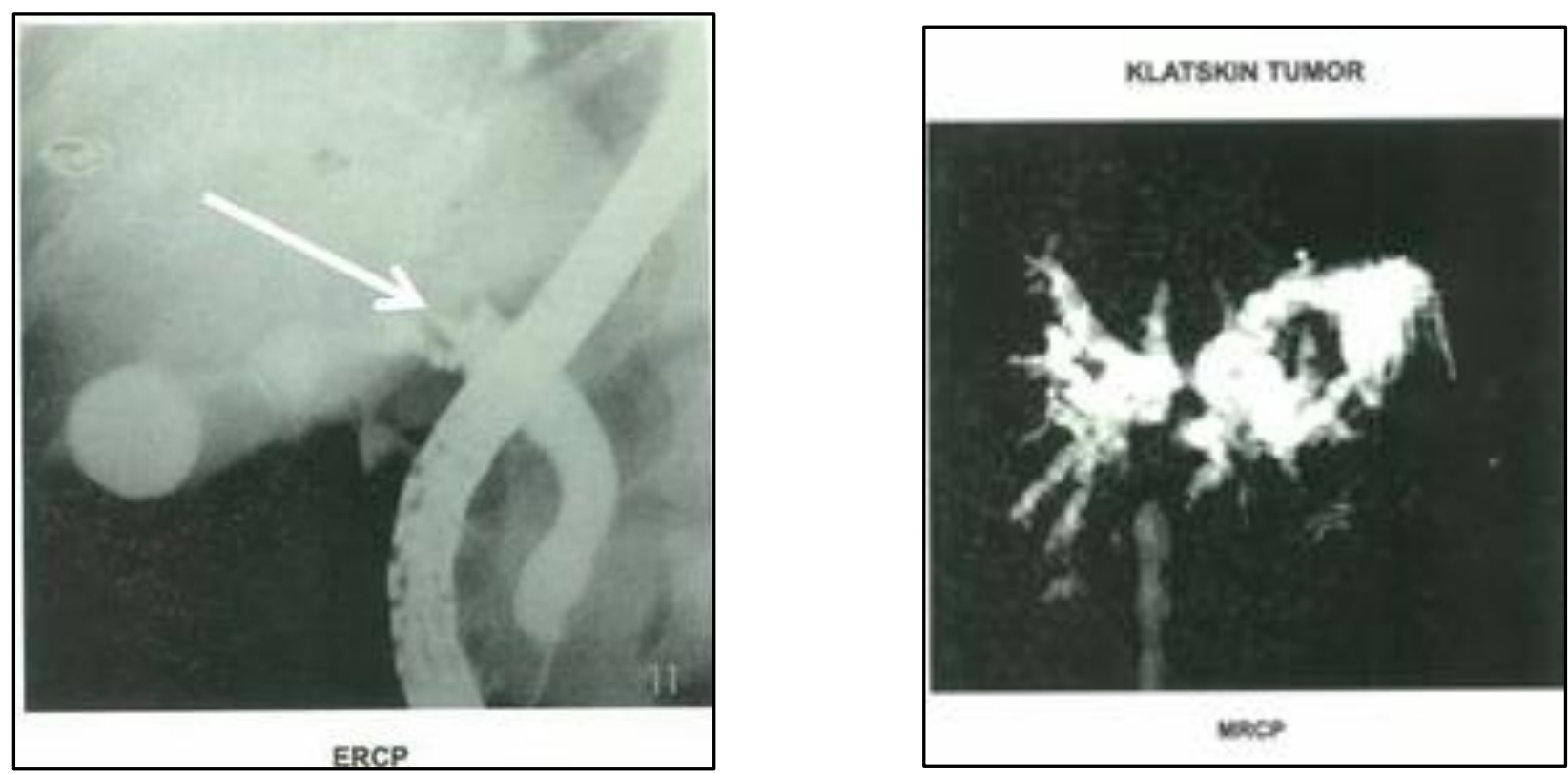

Fig. 1
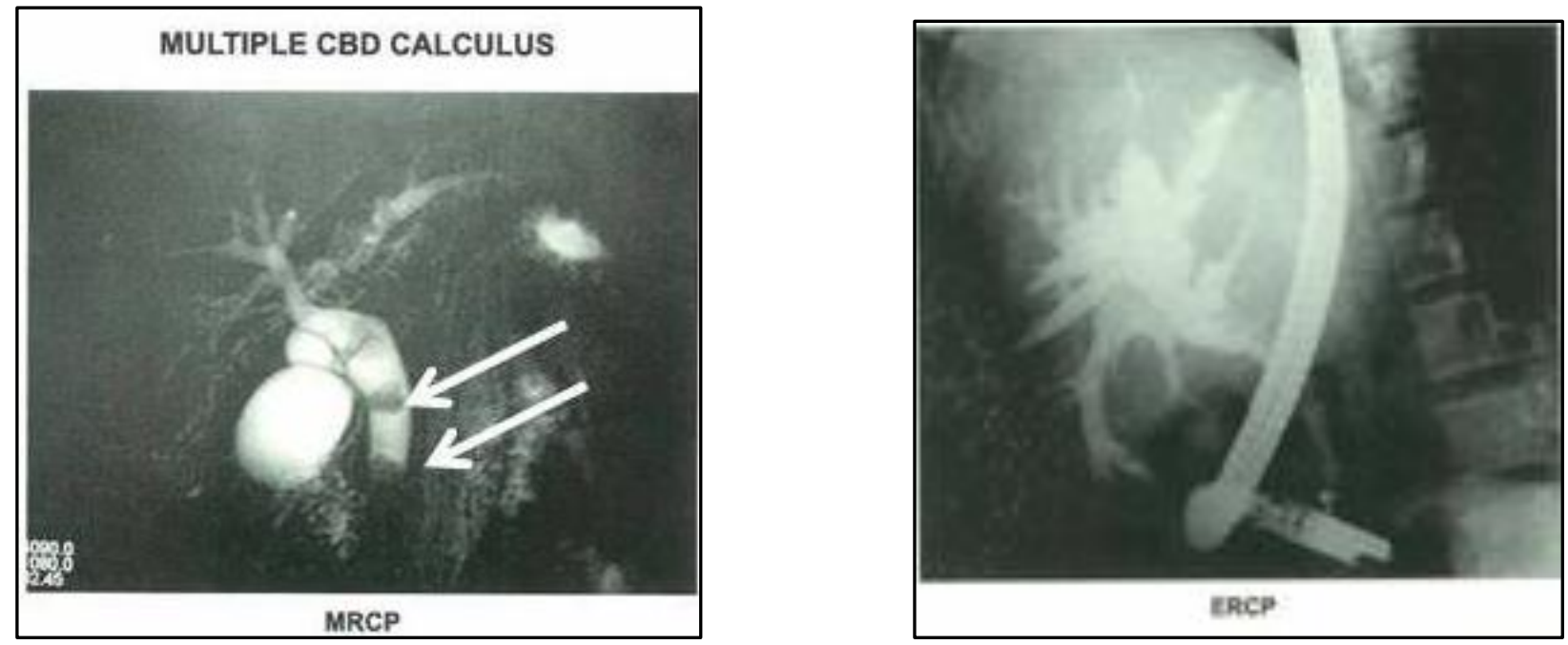

Fig. 3 


\section{RESULTS}

Of the 27 cases, MRCP picked up calculus in 12 cases. ERCP also noted calculus in 12 cases. A small CBD calculus was missed in both MRCP and ERCP. GB calculus in one case was masked in the MRCP images by the bright signal from bile in GB. But the conventional SE images and source images of MRCP were reviewed in that case and GB calculus was diagnosed in that case based on source images.

Stricture was correctly noticed in 8 of the patients in MRCP as well as ERCP. Malignant tumour was diagnosed by MRCP in 6 cases, which was also noted correctly by ERCP.

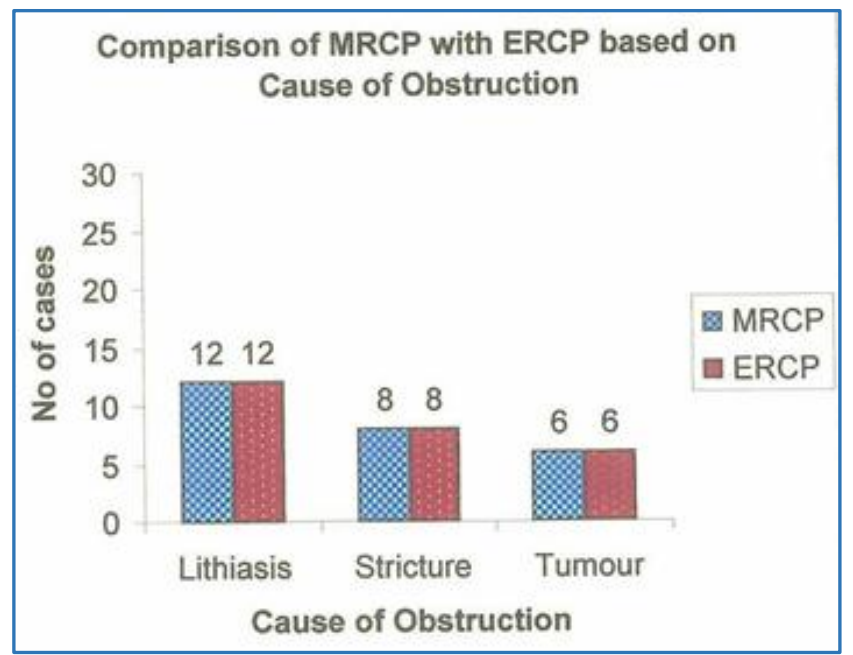

Comparison of MRCP with ERCP based on Extent of Obstruction

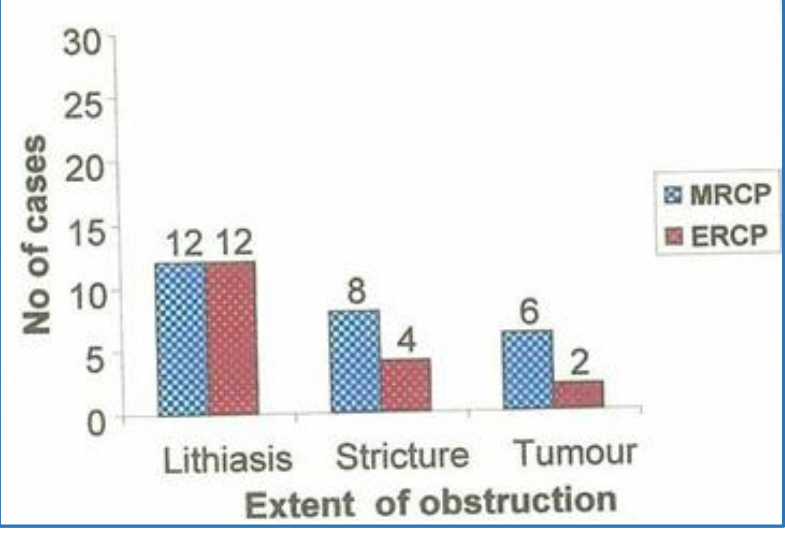

\begin{tabular}{|c|c|c|c|c|c|c|}
\hline \multirow{2}{*}{ Variables } & \multicolumn{3}{|c|}{ MRCP } & \multicolumn{3}{c|}{ ERCP } \\
\cline { 2 - 7 } & Calculus & Stricture & Tumour & Calculus & Stricture & Tumour \\
\hline Sensitivity & $92 \%$ & $100 \%$ & $100 \%$ & $92 \%$ & $100 \%$ & $100 \%$ \\
\hline Specificity & $100 \%$ & $100 \%$ & $100 \%$ & $100 \%$ & $100 \%$ & $100 \%$ \\
\hline $\begin{array}{c}\text { Positive Predictive } \\
\text { Value }\end{array}$ & $100 \%$ & $100 \%$ & $100 \%$ & $100 \%$ & $100 \%$ & $100 \%$ \\
\hline
\end{tabular}

\section{DISCUSSION}

In our study the sensitivity, specificity and positive predictive value of MRCP and ERCP are equal in noting the cause of obstruction.

In our study, MRCP noted the level and extent of obstruction with a sensitivity of $100 \%$. ERCP in our study has a sensitivity of $100 \%$ in noting the level of obstruction and only $65 \%$ in mapping the extent of obstruction.

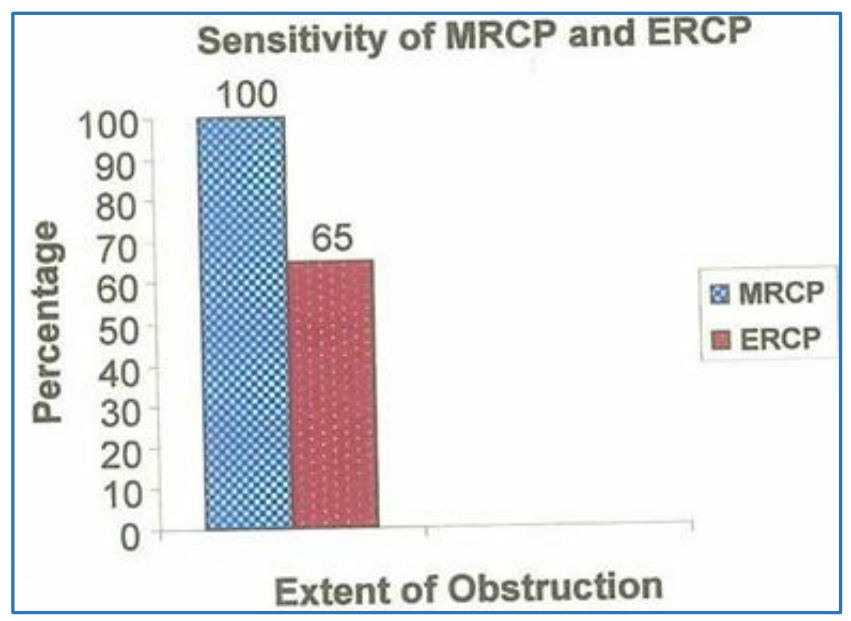

As ultrasonogram is non-invasive and cheaper, it was used as the initial screening investigation in our study. In our study cases ultrasonogram was able to detect biliary obstruction and its level in all cases. In cases of lithiasis, due to excessive bowel gas and obesity it was difficult to detect calculus in CBD in 20\% of cases. ${ }^{10,11}$

Ultrasonogram was able to detect stricture in all cases, but it was very difficult to differentiate benign from malignant stricture in $50 \%$ of cases. In cases of tumour causing biliary obstruction, ultrasonogram had a poor sensitivity to detect the extent of tumour. ${ }^{12}$

Even though the sensitivity, specificity and positive predictive value of MRCP in our study is comparable with ERCP in noting the cause and level of obstruction, MRCP is clearly superior to ERCP in mapping out the extent of obstruction. This is useful in planning further management of the disease. Thus magnetic Resonance Cholangiopancreatography may replace diagnostic Endoscopic Retrograde Cholangiopancreatography for diagnostic purposes following an initial clinical and ultrasonographic examination. ERCP may then be reserved for patients who require intervention in treating biliary obstruction. 


\section{CONCLUSION}

MRCP is a superior imaging modality when compared with ERCP, mainly because it is non-invasive. No radiation exposure or anaesthesia is required. There are no complications of invasive procedure. MRCP can give a detailed map of biliary tree allowing visualisation of ducts proximal as well as distal to the level of obstruction. MRCP can also show the extent of lesion more accurately than ERCP. MRCP can be used as a road map before any surgical intervention.

\section{REFERENCES}

1. Vitellas KM, Keogan MT, Spritzer CE, et al. MR cholangiopancreatography of bile and pancreatic duct abnormalities with emphasis on single-shot fast spinecho technique. Radiographic 2000;20(4):939-57.

2. Lee MG, Lee HJ, Kin MH, et al. Extrahepatic biliary diseases: 3D MR cholangiopancreatography compared with endoscopic retrograde cholangiopancreatography. Radiology 1997;202(3):663-9.

3. Takehara Y. Can MRCP replace ERCP? J Magn Reson Imaging 1998;8(3):517-34.

4. Baron RL. Computed tomography of the biliary tree. Radiologic Clinic of North America 1991;29(6):1235-50.

5. Fulcher AS, Turner MA, Capps GW, et al. Half-Fourier RARE MR cholangiopancreatography: experience in 300 subjects. Radiology 1998;207(1):21-32.
6. Reinhold C, Bret PM. Current status of MR cholangiopancreatography. AJR 1996;166(6):1285-95.

7. Manfredi R, Costomagna G, Brizi MG, et al. Severe chronic pancreatitis versus suspected pancreatic disease: dynamic MR cholangiopancreatography after secretin stimulation. Radiology 2000;214(3):849-55.

8. Soto JA, Barish MA, Yucel EK, et al. Pancreatic duct: MR cholangiopancreatography with a three-dimensional fast spin echo technique. Radiology 1995;196(2):459-64.

9. Miyazaki T, Yamashita Y, Tsuchigame T, et al. MR Cholangiopancreatography using HASTE (half-Fourier acquisition single-shot turbo spin-echo) sequences. AJR Am J Roetgenol 1996;166(6):1297-303.

10. Irie $H$, Honda $H$, Tajima $T$, et al. Optimal $M R$ cholangiopancreatography sequence and its clinical application. Radiology 1998;206(2):379-87.

11. Fulcher AS, Turner MA. MR pancreatography: a useful tool for evaluating pancreatic disorders. Radio Graphics 1999;19(1):5-24.

12. Fulcher AS, Turner MA. HASTE MR cholangiography in the evaluation of hilar cholangiocarcinoma. AJR Am J Roentgenol 1997;169(6):1501-5. 